\title{
RELAPSE IN A CASE OF EARLY SYPHILIS TREATED WITH PENICILLIN
}

\author{
BY \\ C. C. R. DOWNING \\ Medical Officer in Charge of V.D. Clinic, Cardiff Royal Infirmary
}

This paper concerns a relapse in a case of syphilis which had been treated with penicillin alone.

The history of the methods of dosage with penicillin used in the army for the treatment of syphilis is summarized by Osmond (1949). He points out that as few as 600,000 units caused the speedy disappearance of early lesions, and seemed to effect a cure. Relapses, however, came quickly. The total dose was accordingly increased to $1,200,000$ units, and later to $2,400,000$ units, which remained the approved dose for some considerable time. In the present case the latter dosage was used but relapse occurred. In view of the fact that this case represents but one of a very large number treated in a similar way during their army service, it assumes special importance.

\section{Patient's Army History}

A. N., a single man aged 23 in 1949 , served as an infantryman in Italy. About Christmas 1944 he had intercourse with a woman in Naples, and three months later he was taken ill with a sore throat and swollen glands. He reported to his Medical Officer, who found swelling of the inguinal, axillary and submaxillary glands associated with the " sore throat". Acupuncture of one of the inguinal glands and subsequent examination of the extracted fluid showed the presence of Spirochaeta pallida. He was sent to hospital and given 2,400,000 units of penicillin administered by daily injections for a week, presumably in aqueous solution. Signs and symptoms cleared up quickly and he was kept under observation until his discharge from the army in December 1945. The Wassermann reaction was tested once a month for the first six months, again in September 1945, and again just before his discharge in December 1945, when the cerebrospinal fluid was also tested. The result of every test was negative. $\mathrm{He}$ was told to report at a V.D. clinic for further surveillance as soon as he got back to this country.

\section{History after Army Discharge}

The man was first seen and examined at the V.D. Clinic, Cardiff Royal Infirmary, on March 28, 1946. No signs or symptoms of syphilis were present. The Wassermann reaction was negative. He was told to report again in six months time, but after only two months, on May 26, 1946, he came complaining of a recent influenzal attack associated with swelling of the submaxillary and inguinal glands. I can find no note of his case stating whether the glands were found to be enlarged on the date of this examination. A week later, however, he said he felt well and that he was returning to work. Presumably by this time the glands had assumed their normal size and there were no objective signs of syphilis.

On August 22, 1946, the man reported that he had had intercourse on August 15. He was found to have acute gonococcal urethritis which cleared up after two injections of penicillin (ethyl oleate solution), the first dose being 175,000 and the second 250,000 units. During the interval of two weeks between these doses he was given by mouth $20 \mathrm{~g}$. of sulphathiazole, $4 \mathrm{~g}$. daily for five days. By the end of September the urethral infection had cleared up completely and he was kept under observation until he was finally discharged on January 20, 1947.

It should be emphasized here that during the whole time he attended the clinic the fact that he might have acquired a double infection was kept well in mind. At no time did any sign or symptom occur which suggested syphilis, and the Wassermann reaction remained, consistently negative during the whole period of observation.

Twenty months later the patient came again, on April 12, 1948, complaining of swollen glands. The inguinal and axillary glands were found to be affected. The Wassermann reaction was negative and he was then referred to the Medical Out-patients' department at the Cardiff Royal Infirmary for the opinion of a consultant physician. It appears that a diagnosis of simple adenitis was made and that the man was asked to report again in three months. This he did not do and nothing was seen or heard of him until April 21, 1949, when he reported at the V.D. Clinic, saying that he had been sent by the Ear, Nose and Throat surgeon of the Cardiff Royal Infirmary. He had caught a chill in December, 1948, and this had exacerbated old middle ear disease (right) with the result that a mastoidectomy had to be done. While he was in the ward for this operation his blood was examined and the Wassermann and Kahn reactions found to be strongly positive. On examination the inguinal and axillary glands proved to be swollen, painless, and characteristic of syphilis. Repeated 
Wassermann and Kahn tests confirmed the strong positive reaction. A course of ten injections of neoarsphenamine and bismuth, at weekly intervals, was then begun. The drugs were given concurrently, the total dosage being $5 \cdot 85 \mathrm{~g}$. neoarsphenamine and $2 \mathrm{~g}$. bismuth. At the end of the course the glands were all normal and the Wassermann reaction negative. The man felt much improved in health and resumed work.

\section{Discussion}

The patient is of an intelligent type and, so far as it is possible to judge, reliable. I believe him when he says that he has never run the risk of getting venereal disease apart from the two occasions already admitted to. There is nothing to show that he acquired a double infection on August 15, 1946. Had he done so, I do not think the total dose of 425,000 units of penicillin in ethyl oleate would have delayed the appearance of positive Wassermann and Kahn reactions for nearly three years. Neither do I think that symptoms and signs of syphilis would have been delayed for twenty months. The assumption that adenopathy present in May, 1946, was due to syphilis implies that he would have been sufficiently protected against reinfection with that disease by August, 1946. His condition then would appear to be a relapse in a case of early secondary syphilis, after inadequate penicillin treatment.

Certain points are of special interest : (1) The first recurrence appeared one year, the second three years, and the third four years after treatment. There was a latent period of two years between the first and second recurrence, and of one year between the second and third ; (2) In spite of these three recurrences the Wassermann reaction remained negative over a period of four years ; (3) Recurrence on each occasion affected the glands involved at the start of the disease. No signs of syphilis were found in any other part of the body.

\section{Conclusion}

This case emphasizes the advisability of following the later policy of the army, whereby the total dosage was increased to $4,800,000$ units of penicillin, and it became customary to supplement the penicillin treatment with at least one course of neoarsphenamine and bismuth injections (5.85 $\mathrm{g}$. neoarsphenamine and 2-2.5 g. bismuth).

\section{REFERENCE}

Osmond, T. E. (1949). British Journal of Venereal Diseases, 25, 101. 